\title{
Yoga and relaxation for promoting public health: A review of the practice and supportive research
}

\author{
Krzysztof Stec \\ Institute of Physical Education, Tourism and Physiotherapy, Jan Długosz University in Częstochowa, Poland
}

\section{Summary}

The purpose of this review is to present yoga as an important tool for both disease prevention and health care. Yoga involves a holistic approach that lacks the mechanistic fragmentation of the impact on individual organs and body systems, which arises from much of the specialization found in modern medicine. Lifestyle diseases are increasingly a problem. The incidence of diabetes, hypertension, atherosclerosis, cancer, mental illness and obesity is increasing worldwide. This is true even of countries that, until recently, followed a traditional way of life. Technology, the pace of life, stress, and reduced physical activity serve to degrade the general level of health in societies across the globe. In Western societies, these factors have raised the demand for preventive and therapeutic antidotes, leading Westerners to turn to traditional yoga, which is, however, often modified to the point of distorting its essence. In its original nature yoga is a non-religious, psychosomatic system based on natural laws, inspired by science to act on the body in a way that is integrated into the natural world. The system of Ayurvedic medicine works in parallel with yoga, aiming at the same holistic effect. Both it and the various elements of yoga, in particular asanas (postures), are the means of effecting beneficial changes in psychosomatic functioning. Yoga itself relaxes and strengthens physical movement, focusing particular attention on the mobility of the spine. It is also the perfect medium for achieving mental balance. These properties of yoga have made it useful in the treatment of cancer and other modern diseases, in slowing the body's aging process, and in achieving general welfare and well-being. More intense forms of yoga practice, such as the ancient method of fitness training called Suryanamaskar, have demonstrated their effectiveness in preventing and treating cardiovascular diseases, respiratory ailments and other conditions.

\section{Key words: Yoga - Relaxation - Public health - Lifestyle diseases - Stress}

\section{Introduction}

Modern medicine has made great progress in treating infectious diseases such as cholera, smallpox and tuberculosis. Despite the worldwide HIV crisis, the overuse of increasingly ineffective antibiotics, the Ebola virus, and medical scientists' seemingly well-founded fears about what virus might next befall us, until the appearance of COVID-19 pandemia it seemed that communicable diseases are not currently the threat to most human populations that they once were. Studies show that they are no longer the main cause of death in the modern world; instead, noncommunicable diseases (NCDs) have reached epidemic proportions [4]. Such NCDs are lifestyle related and encompass cardiovascular problems, including atherosclerosis, type II diabetes and other metabolic disorders, many forms of cancer, respiratory diseases, and others [28].
Hunter and Reddy [27] related the four NCD groups named above to four behavioral risk factors: (a) unhealthy diet, (b) overuse of alcohol, (c) use of tobacco and (d) a sedentary lifestyle (physical inactivity). However, the main underlying risk factor for NCDs is chronic stress, whether its impact is direct or indirect [1]. In the APA's survey, $42 \%$ of respondents reported not doing enough to control their own stress. Various relaxation techniques, including yoga, could not only prove to be very helpful but are also without harmful side effects and are relatively inexpensive to apply.

The aims of this review are to explain the wider sense of what the practice of yoga means and to present research data from a range of sources that assess the effectiveness of such practice in assisting the treatment or management of many disorders, and in thus making a positive impact on public health. 


\section{Yoga's multifaceted health-promoting properties}

Yoga, as a mind-body practice, does not focus merely on physical activity. While in the West yoga is viewed primarily as a form of physical activity, in fact there are three other essential components, usually forgotten or considered only secondarily: (a) breathing exercises, (b) deep relaxation and (c) focusing of the mind. In fact, the true synonym for or meaning of yoga, samadhi (the state of integrated homeostasis), has shifted to asanas (yogic postures) [26]. Yoga as a system has always approached health concerns in an integrated way, viewing a person as a whole entity and claiming that, when one part is sick, then the whole body is also sick. The concept of samatvam, a homeostasis or state of balance in the individual, has been strongly emphasized in Indian scriptures. One of the meanings of the word yoga itself is samatvam: samatvam yoga ucyate (yoga is equilibrium) is an aphorism from the Bhagavad Gita, chapter 2, verse 48 [20]. A related, principal meaning of the word yoga is sangati or harmony. According to yoga, positive health depends upon the harmony of all bodily and mental functions [34].

As mentioned previously, yoga considers man as a whole; it does not divide a person into categories such as organs, mind, spirit, etc. This process of integration means that yoga has developed methods to counteract the effects of those environmental and cultural influences that may contribute to disintegration. Whereas a diseased body or mind would certainly be liable to contribute to such disintegration, a healthy body and mind are necessary prerequisites to the performance of the more advanced yogic practices. It should be understood that the science of yoga does not deal with issues of therapy in the normal sense of the word; rather, it has laid down certain hygienic, i.e. health-related, methods that are applicable to body and mind. These hygienic methods are known as kriya yoga. Kriya means a purificatory and reconditioning process. In fact, classical yoga generally deals with only mind and spirit, and the fundamental text on yoga - known as the Yoga Sutras of Patanjali (PYS) - treats the body and mind as one whole [26]. For that reason certain physical exercises like asanas and pranayamas (yogic breathing) are an essential precursor to more advanced psychological practices involving relaxation and focusing of the mind. All of these practices aim at integration of psychophysiological processes known as samadhi (samadhibhavanarthah - PYS II-2) [26]. These practices stabilize psycho-physiological mechanisms so that there are fewer tendencies towards imbalance brought about by internal or external stimuli. Any disease (vyadhi) is considered a potential psycho-physiological disturbance (PYS I-30) [26]. In the treatment of disease one may think of two defenses. One is to investigate and eradicate the offending factor so as to leave the body to regain its health on its own; the other is to put up a successful fight against the 'offenders'.
The body has inherent intelligence and powers to develop specific immunity and fend off the offending factors successfully [34]. Since the discovery of bacteria, viruses and other pathogens, traditional medicine has focused primarily on the first method of defense, though it is not entirely ignorant of the second pathway. In practical terms, however, the first path, to investigate and eliminate the offending factor, is the way of an average medical practitioner. After traditional medical treatment of an acute disease, patients are typically left to themselves, and, for chronic diseases, traditional medical providers may continue prescriptions but are otherwise prone to refer patients to 'alternative medicine providers' (perhaps including yogis). On the other hand, physical medicine, including physiotherapy, is more occupied with the rehabilitation of physical disorders (for example locomotor disabilities) than non-physical ones.

The philosophical approach of relaxation methods and techniques such as yoga is that one needs to strengthen oneself rather than waste time trying to eliminate a persistent and perhaps ineradicable offending factor. The role of yoga for man has been described thus: "For a man who wears shoes, the whole earth would indeed seem as if covered with soft leather" proclaims the Yoga Vashishtha [61]. That text shows yet one more of the many meanings of the word 'yoga', that is sannahana or to be armored and well prepared.

One of the important goals of yoga is health, but positive health in this sense is much more than freedom from disease; it is a jubilant and energetic feeling of well-being together with an abundant capacity of the immune system to resist any specific toxic agents. This concept of health does not mean merely the ability 'somehow' to work or function, but the possession of an exuberant capacity to act that simply does not allow any apathy or laziness to arise. This is in contrast to the state of modern man, who seems to be deprived of much of his internal capacity to fight personal health battles and, with the progress of technology, tends to rely increasingly on external measures.

Yoga accomplishes therapy through various means, such as physical purification procedures (shatkarmas), diet correction (mitahara), correction of psychological attitudes (yamas and niyamas), restoration of psychophysiological mechanisms through relaxation (asanas, pranayamas, pratyahara), and focusing the mind through meditation (dharana, dhyana). In this approach it is very important to change the internal attitude (bhava) as follows: "I myself am responsible for my own well-being and my health, and I should drop the attitude that says my health is the responsibility of a healthcare system or my family doctor." The above-mentioned parts (angas) of the full yoga system all closely collaborate in the process of purification and reconditioning of a human being, and as 
a result, the process of $s a m+a d+d h a$ (to put together as one whole) can take place.

\section{Material and methods}

Only papers in English were considered. Firstly, abstracts and titles were identified through a PubMed database search as well as selected Indian yoga research institutions. Special focus was placed on randomized controlled trials (RCT). Key words used were yoga and Ayurveda, yoga and anti-stress, yoga and metal conditions, yoga and cardiorespiratory conditions, yoga and musculoskeletal conditions, yoga and cancer, yoga and geriatrics, yoga and prevention, and yoga and wellness. With very few exceptions the majority of the quoted literature is less than 20 years old.

\section{Yoga and Ayurveda}

The science of yoga has always been very close to the science of Ayurveda (ayur - life, veda - science), which is widely considered to be the oldest healing (medical) system. This science of life is based on the sutras from the Atharvaveda and claims that about $98 \%$ of all diseases come from the digestive system [30]. Interestingly, in support of this idea, in the 1990s, King's College of London announced, from its own research reviews and understanding, that more than $90 \%$ of all diseases are related to the digestive system. From a study of ancient yogic manuscripts it becomes clear that a healthy diet focusing on fresh, unprocessed, non-GMO (genetically modified organisms) plant-based vegetarian or vegan foods is the optimal choice. The Campbells [11] called that special diet a whole-food, plant-based diet, which is quite different from the conventional concept of vegetarianism. Yoga and Ayurveda incorporate mindfulness into the processes of food preparation, serving and food consumption, recognizing that these processes are more subtle aspects of the nutritional value that foods bring us [53]. In fact, the central process in Ayurvedic treatment is panchakarma, or five therapeutic procedures that create a single comprehensive system of purification of toxins from the body, of rejuvenation and of restoration of homeostasis on the basis of natural law [29]. The Charaka Samhita, the basic text on Ayurveda, bases its explanation of human structure and function on the Upanishads and says that real health can be obtained only when total liberation from worldly matters is achieved [31].

\section{Yoga as an anti-stress exercise system}

Many authors view yoga as a primary system of exercises for bringing about the relaxation response [4] and for helping to manage modern life stresses - both of which have been well documented over the last 50 years [51].
Maintaining health-related fitness and managing stress are the leading reasons why most people opt for yoga [45]. Stress management is critical for contending with conditions such as obesity, diabetes and insomnia, digestive problems, and heart disease.

Chronic stress is known to influence the aging process by telomerase shortening. Lower telomerase activity, and shorter telomere length are well-known determinants of cell senescence and longevity, and they are, moreover, affected by psychological stress, both perceived stress and chronicity of stress [18]. Further research could help to determine if yogic relaxation techniques would be useful for older populations in this respect.

Too much stress may elicit negative behavioral patterns such as over- or under-eating, using alcohol, tobacco, or other drugs, while healthy diet and exercise habits are abandoned.

Every disease appears to provide a psychophysiological rationale for the application of relaxation practices. In the case of yoga, it appears to play a pivotal role in combating stress and inflammatory conditions. Inflammatory conditions are common in most NCDs; chronic stress affects almost every bodily system and can have both a direct and an indirect impact on disease [15]. By decreasing sympathetic nervous system (SNS) activity, relaxation can reduce the harmful effects of chronic stress. Some research seems to confirm that the changing of lifestyle factors, such as exercise, diet, stress management and sleep quality, can improve underlying biological processes responsible for health and well-being [34].

\section{Yoga as a therapy for mental conditions}

It is widely accepted that anxiety is a dysfunction of the stress response system, the autonomic nervous system and the hypothalamic-pituitary-adrenal axis. In the presence of anxiety, hyperactivity of the sympathetic nervous system or hypoactivity of the parasympathetic nervous system has been documented by Thayer et al. [59]. As noted, these system imbalances have a major negative impact on all systems of the body, including the cardiovascular, respiratory and immunological systems [15]. Yoga can help to boost these systems through such mechanisms as reducing the activity of the sympathetic nervous system and increasing the activity of the parasympathetic nervous system. It may also reduce the activity of the limbic system or modulate cognitive functions in such a way as to correct misinterpretation of a threat, essentially increasing the ratio of higher brain reasoning over lower brain emotional (and related physiological) over-reactivity. For example, there are numerous studies that indicate a strong positive impact of various yogic practices on stress and anxiety levels [32]. However, it should be noted that, owing to the diversity of conditions treated and to the low quality of many of the studies, it has still not been conclusively 
demonstrated that yoga is effective in treating anxiety or anxiety disorders in general. Nevertheless, there have been encouraging results, particularly with respect to obsessive compulsive disorders.

\section{Yoga as a therapy for cardiorespiratory conditions}

Several studies suggest that yoga lowers such risk factors for cardiovascular disease as blood pressure, serum lipid profile, smoking, obesity and psychophysiological stress $[24,33,42,46,58]$. These studies show that yoga acts on several levels when helping to prevent cardiovascular disease. Yoga has been shown directly to facilitate atherosclerotic regression, to help decrease cardiac arrhythmias, and to be useful in cardiac rehabilitation [35].

Obstruction of airflow in the lungs includes such chronic conditions as emphysema, asthma and bronchitis, which can frequently overlap in a single patient [23]. Such chronic obstructive pulmonary diseases are marked by chronic inflammation of the air passages, lung tissues and pulmonary blood vessels due to exposure to various irritants. Milanese et al. [41] showed that deep and slow breathing helped dilate air passages and might be of potential benefit in asthma, though no conclusive research has yet affirmed this reasonable inference. It is well known that pranayama involves slow and deep breathing combined with its own distinct element of breath holding; the correct proportion of inhalation to holding to exhalation is in the ratio of 1:4:2. Even fast yogic breathing techniques always include the slow exhalation part with breath holding [34]. Slow breathing has been shown to improve baroreflex sensitivity [5] and lower chemoreflex sensitivity [52], both of which help to reduce activity of the sympathetic nervous system [48]. In their meta-analysis, Liu et al. [36] found that yoga training increases forced expiratory volume in 1 second $\left(\mathrm{FEV}_{1}\right)$ and overall lung function and exercise capacity by strengthening breathing muscles; it may therefore be useful in the case of chronic obstructive pulmonary disease [56].

\section{Yoga as a therapy for musculoskeletal conditions}

Musculoskeletal (MSK) afflictions are the second leading cause of disability worldwide [62]. Lower back pain is the most prevalent, with neck pain following closely behind [19]. Regular physical exercise is very important in the proper management of MSK disorders. The physical benefits provided by yoga depend heavily on the components included in the practice, and yoga offers a very rich repository of techniques and methods. Research findings from various studies vary considerably because they differ with respect to those components and the ways in which they are presented and executed. Based on recent experiments, at least one of the fundamental yogic practices the dynamic version of Suryanamaskar (Sun Salutations)
- changes both the physical fitness and the anthropometric characteristics of those who practice it $[54,55]$. Yoga is probably the most famous in the West for stretching activity that improves flexibility and increases joint mobility $[39,56]$. There are yoga styles which emphasize isometric activities that develop strength [43]. The performance of asanas in that way enhances joint stability through greater muscular strength. There are a number of studies indicating that yoga reduces pain associated with disability, as described in a recent meta-analysis by Bussing et al. [10].

Yogic practices have been used as a therapy for a number of back disorders, including back pain, scoliosis and kyphosis. Worldwide, lower back pain (LBP) has been prevalent in about $80 \%$ of the population to the extent that most adults are expected to experience it at least once in a lifetime [2]. Chronic LBP has become the chief cause of pain and disability. The specific mechanisms by which yoga can help LBP are unknown, but considering the multidimensionality of a yogic approach, it is apparent that several factors are conducive to the overall positive results, including (a) increased body awareness, and, related to that, (b) the correction of wrong movements or poses, (c) a release of mental and body stress, and (d) increased physical activity. Cramer et al. (2013) completed a metaanalysis of ten studies for low back pain and concluded that there was a beneficial impact of yoga on LBP.

\section{Yoga as a therapy for cancer}

Studies in the United States show that complementary and alternative medicine therapies are used by approximately $50 \%$ of cancer survivors [39]. The mindbody practices offered by yoga during and after cancer treatment help to manage stress, the side-effects of other treatments, and other symptoms. It is a well-known fact that stress negatively affects each and every biological system in the body [15]. Stress impacts immunity in a very negative way, lowering an effective immune response even while increasing inflammation to create new health problems [37]. Separate meta-analyses by Buffart et al. [9] and Harder et al. [25] conducted on the physical and psychosocial benefits of yoga for cancer patients and cancer survivors both found overall positive effects from yoga practice. Although the studies that are available have had such limitations as being primarily focused on women with breast cancer, they have collectively produced sufficient evidence of positive outcomes as to justify recommending yoga for adults undergoing cancer treatment $[6,12,21,60]$. In several cases yoga practice led to significant improvements, and there were no reported adverse effects. Importantly, yoga has provided cancer survivors with various psychosocial benefits such as vigor, positive emotional well-being, and a decrease in levels of stress, anxiety and depression. 


\section{Yoga for geriatrics}

More senior citizens are turning away from pharmacological treatment and towards lifestyle modification and various behavioral approaches to health management. The science of yoga is well suited to making a positive impact on senior citizens' lives since, besides there being many psychosomatic benefits of yogic practice, there is a positive connection between spirituality and late-life health. McCullough et al. [40] in their meta-analysis of 29 articles concluded that individuals scoring higher on the measures of their religious practices were about $30 \%$ less likely to die during the study period than those scoring lower. A number of studies have provided information relevant to yoga practice about physical changes that occur with increasing age. For example, some researchers have reported a slow decrease in body mass [7] or a decline in muscle strength [49], while others have noted changes in cardiovascular structure [17]. According to Buchner et al. [8] this physical degradation causes, in turn, a decline in overall life quality. Many kinds of age-related bodily decline respond well to yogic practices, which, by their very nature, have an integrated impact on the whole psychosomatic organism. Yoga addresses these aspects at the musculoskeletal, cardiovascular, psychosocial, cognitive and spiritual levels. Stec et al. [57] and Stec et al. [53] found that active people regularly engaging in that particular form of the fundamental yogic practices called Suryanamaskar, which combines asanas, pranayamas and a focused mind, experienced a very favorable impact on their cardiovascular function, in that they had a lowered maximal heart rate and a significantly increased stroke volume when compared to a sedentary person. Furthermore, physical activity increases the mineral density of bones; this positive association was found by Phoosuwan et al. [44]. In addition, cognitive decline in old people has been slowed by such activities as meditation or self-enquiry [47]. Other negative mental symptoms and health risk factors among the elderly, such as stress, anxiety and depression, can also be successfully treated by various yogic techniques, as discussed above.

\section{Yoga for prevention and wellness}

As noted earlier, until recently most humans died from communicable diseases. In the 20th century the principal cause of death shifted towards NCDs to the extent that, today, nearly two-thirds of deaths worldwide are attributable to NCDs [3]. Statistics currently show that five of the seven top causes of death are lifestyle-related NCDs - heart disease, cancer, chronic lung disease, stroke and type 2 diabetes [28]. These chronic lifestyle diseases are attributable to such factors as poor nutrition, too much stress, a sedentary lifestyle, and the consumption of tobacco and alcohol [3]. A yogic lifestyle directly addresses all of these factors. In addition to physiological changes that have an impact on health, a yogic lifestyle also changes behavior due to the increased mindfulness, body awareness, and feeling of wellbeing that accompany yoga practice [50]. Overall, increasing evidence from research studies, clinical, experimental and epidemiological, shows yoga to be useful in promoting health prophylactically and enhancing general well-being. One of the best ways of making a yogic lifestyle more available as a tool of preventive medicine would be the inclusion of yoga in school curricula and in the workplace.

Recently, new branches of medicine such as mind-body medicine and lifestyle medicine, as well as other behavioral therapy systems, have become more popular among patients, but healthcare systems continue to neglect these new approaches and to emphasize instead invasive interventions such as surgery and pharmaceutical solutions. It is perhaps the case that improved functioning resulting from psychological therapies, for example cultivating forgiveness, acceptance or happiness, is harder to quantify than it is to measure heart rate or blood pressure, but such psychological approaches are at least as important to overall feelings of health and well-being as those resulting in physically measurable improvements.

When weighing the merits of yoga therapy, it is important to realize that there are numerous schools and styles of yoga, and new 'brands' appear every year. There are also traditional yoga systems, such as those developed by the Kaivalyadhama Yoga Institute, The Yoga Institute, S-VYASA Yoga University, and Himalayan Yoga. It is possible to distinguish alignment-based styles like that of BKS Iyengar of Pune, and its derivatives such as Anusara Yoga, Purna Yoga or San Jeevan Yoga; and, based on the Krishnamacharya tradition, to distinguish Ashtanga Yoga, Vinyasa Yoga, Power Yoga, and the more gentle and therapeutic approach of Svatha Yoga. In this list one could also include tantric Gitananda Yoga and the Bihar School of Yoga. Future research should be directed towards determining whether these differences are merely stylistic or whether any of them can provide substantive benefits. It is also to be expected that medical researchers will turn increasingly to comparative studies to help discern how yoga compares to the various behavioral therapies that may be considered to fall under the heading of 'alternative medicine'.

\section{Conclusions}

Yoga therapy may have important practical value for public health, provided its core principles are not diluted in the adaptation of the practices to Western cultures. Some modern yoga schools have tended to blend yoga with various behavior therapies in an effort to obtain acceptance or to add 'elegance' to yoga demonstrations. The Western medical system tends to see yoga as a kind of exercise 
therapy. Although therapeutic yogic procedures contain exercises, or rather body postures, their effect on physiology is not equivalent to that of ordinary dynamic and vigorous exercises. Yoga therapy consists of more than physical therapy exercise; it also provides a comprehensive composite procedure and philosophy that includes all aspects of the human personality. In this perspective, yoga affects humans holistically, providing them with somatic and psychological improvement and comfort. In that sense it works incomparably better than modern clinical medicine, which just focuses on the treatment of disease entities and is not able to provide care in the same way as yoga for the holistic well-being of the patient. Yogic therapy appears to be useful in the treatment of some chronic diseases. Though some hatha yoga exercises help with metabolic dysfunctions and some physical deformities and disabilities, yogic therapy's real place lies in mind-body healing (psycho-somatic medicine). Yogic therapy is of less help in treating acute diseases but of much more help in preventing disease and in maintaining long-term health. The suggestion of the author of this paper would be for practitioners to stay focused on the application of yoga as therapy within the original interpretation of yoga as developed by the yogis, seers and rishis of the past. Yoga has long, deep, theoretical, philosophical, and spiritual roots as well as burgeoning new scientific support. It is a system that is based on the real experience and reliable observations of ancient 'intuitive scientists' or 'inspired' sages accumulated over millennia, while modern yoga research is in its inceptive stage only.

\section{Conflict of interest: Authors state no conflict of interest.}

\section{References}

1. American Psychological Association. Stress in America - February 4, (2015) Available on https://www.apa.org/ news/press/releases/stress/2014/stress-report.pdf (Accessed 16.3.2017).

2. Balagué F., Mannion A.F., Pellisé F., Cedraschi C. (2012) Non-specific low back pain. The Lancet, 379(9814): 482-491.

3. Bauer U.E., Briss P.A., Goodman R.A., Bowman B.A. (2014) Prevention of chronic disease in the 21st century: elimination of the leading preventable causes of premature death and disability in the USA. The Lancet, 384(9937): 45-52.

4. Benson H., Klipper M.Z. (2001) The Relaxation Response. HarperCollins, USA.

5. Bernardi L., Gabutti A., Porta C., Spicuzza L. (2001) Slow breathing reduces chemoreflex response to hypoxia and hypercapnia, and increases baroreflex sensitivity. J. Hypertens., 19(12): 2221-2229.
6. Blank S.E., Kittel J., Haberman M.R. (2010) Active practice of Iyengar yoga as an intervention for breast cancer survivors. Int. J. Yoga Ther., 15: 51-59.

7. Bray G. (Ed.) (1979) Obesity in America. Washington: DC: Department of Health, Education and Welfare.

8. Buchner D.M., Larson E.B., Wagner E.H., Koepsell T.D., de Lateur B.J. (1996) Evidence for a non-linear relationship between leg strength and gait speed. Age Ageing, 25(5): 386-391.

9. Buffart L.M., van Uffelen J.G, Riphagen I.I., Brug J., van Mechelen W., Brown W.J., Chinapaw M.J. (2012) Physical and psychosocial benefits of yoga in cancer patients and survivors, a systematic review and meta-analysis of randomized controlled trials. MC Cancer, 12: 559.

10. Büssing A., Ostermann T., Lüdtke R., Michalsen A. (2013) Effects of yoga interventions on pain and pain-associated disability: a meta-analysis. J. Pain, 13(1): 1-9.

11. Campbell T.C., Campbell T.M. (2006) The China Study: The Most Comprehensive Study of Nutrition Ever Conducted and the Startling Implications for Diet, Weight Loss and Long-term Health. Dallas, USA: BenBella Books.

12. Carson J.W., Carson K.M., Porter L.S., Keefe F.J., Seewaldt V.L. (2009) Yoga of awareness program for menopausal symptoms in breast cancer survivors: Results from a randomized trial. Support Care Cancer, 17: 1301-1309.

13. Choudhary R., Stec K. (2008) Effect of dynamic suryanamaskar on vital capacity of physical education students. Indian J. Phys. Edu. Sport Med. Exerc. Sci., 8(2): 11-20.

14. Choudhary R., Stec K. (2010) The effects of dynamic suryanamaskar on flexibility of university students. J. Adv. Dev. Res., 1(1): 45-48.

15. Chrousos G.P., Gold P.W. (1992) The concepts of stress and stress system disorders. Overview of physical and behavioral homeostasis. JAMA, 267(9): 1244-1252.

16. Cramer H., Haller H., Lauche R., Dobos G. (2013) A systematic review and meta-analysis of yoga for low back pain. Clin. J. Pain, 29(5): 450-460.

17. Di Bello V., Lattanzi F., Picano E., Talarico L., Caputo M.T., Di Muro C., Santoro G., Lunardi M., Distante A., Giusti C. (1993) Left ventricular performance and ultrasonic myocardial quantitative reflectivity in endurance senior athletes: an echocardiographic study. Eur. Heart J., 14(3): 358-363.

18. Epel E.S., Blackburn E.H., Lin J., Dhabhar F.S., Adler N.E., Morrow J.D., Cawthon, R.M. (2004) Accelerated telomere shortening in response to life stress. Proc. Natl. Acad. Sci. USA, 101(49): 17312-17315.

19. Fejer R., Kyvik K.O., Hartvigsen J. (2006) The prevalence of neck pain in the world population: a systematic critical review of the literature. Eur. Spine J., 15(6): 834-848.

20. Feuerstein G., Feuerstein B. (2014) The Bhagavad-Gita: A New Translation. Shambhala. 
21. Galantino M., Cannon N., Hoelker T., Iannaco J., Quinn L. (2007) Potential benefits of walking and yoga on perceived level of cognitive decline and persistent fatigue in women with breast cancer. Rehabil. Oncol., 25: $3-16$.

22. Gitink R.A., Yeh G.Y., Goldie S.J., Hunink M.G. (2016) The effectiveness of yoga in modifying risk factors for cardiovascular disease and metabolic syndrome: A systematic review and meta-analysis of randomized controlled trials. Eur. J. Prev. Cardiol., 23(3): 291-307.

23. Global Initiative for Obstructive Lung Disease, 2018 Global Diagnosis, Management, and Prevention of Chronic Obstructive Pulmonary Disease - 2018 Report. Retrieved on July 20, 2019 from www. goldcopd.org.

24. Gupta S.K., Sawhney R.C., Rai L., Chavan V.D., Dani S., Arora R.C., Selvamurthy W., Chopra H.K., Nanda NC. (2011) Regression of coronary atherosclerosis through healthy lifestyle in coronary artery disease patients Mount Abu Open Heart Trial. Indian Heart J., 63(5): 461-469.

25. Harder H., Parlour L., Jenkins V. (2012) Randomized controlled trials of yoga interventions for women with breast cancer: a systematic literature review. Support Care Cancer, 20(12): 3055-3064.

26. Hariharananda-Aranya S. Yoga Philosophy of Patanjali. (1981) Calcutta University Press, Calcutta.

27. Hunter D.J., Reddy K.S. (2013) Noncommunicable diseases. N. Engl. J. Med., 369(14): 1336-1343.

28. Jones D.S., Podolsky S.H., Greene J.A. (2012) The burden of disease and the changing task of medicine. $N$. Engl. J. Med., 366(25): 2333-2338.

29. Joshi S.V. (1998) Ayurveda and Panchakarma - The Science of Healing and Rejuvenation. Delhi, India: Motilal Banarsidass.

30. Kashyap R.L. (2011) Atharva Veda (Sanskrit Text, English Translation and Explanatory Notes) (Set of 6 Volumes). India: Sri Aurobindo Kapali Sastry Institute of Vedic Culture.

31. Kimura K.K. (2016) Yoga Therapy Theory - Modern methods based on traditional teachings of human structure and function. Japan: Japan Yoga Niketan.

32. Kirkwood G., Rampes H., Tuffrey V., Richardson J., Pilkington K. (2005) Yoga for anxiety: A systematic review of the research evidence. Br. J. Sports Med., 39: 884-891.

33. Kochupillai V., Kumar P., Singh D., Aggarwal D., Bhardwaj N., Bhutani M., Das S.N. (2005) Effect of rhythmic breathing (Sudarshan Kriya and Pranayam) on immune functions and tobacco addiction. Ann. N. Y. Acad. Sci., 1056: 242-252.

34. Kuvalayananda S., Vinekar S.L. (2017) Yogic Therapy. Lonavla, India: O.P. Tiwari, Kaivalyadhama.

35. Lakkireddy D., Atkins D., Pillarisetti J., Ryschon K., Bommana S., Drisko J., Vanga S., Dawn B. (2013) Effect of yoga on arrhythmia burden, anxiety, depression, and quality of life in paroxysmal atrial fibrillation: the YOGA My Heart Study. J. Am. Coll. Cardiol., 61(11): 1177-1182.

36. Liu X.C., Pan L., Hu Q., Dong W.P., Yan J.H., Dong L. (2014) Effects of yoga training in patients with chronic obstructive pulmonary disease: a systematic review and meta-analysis. J. Thorac. Dis., 6(6): 795-802.

37. Lutgendorf S.K., Sood A.K. (2011) Biobehavioral factors and cancer progression: physiological pathways and mechanisms. Psychosom. Med., 73(9): 724-730.

38. Mandroukas A., Vamvakoudis E., Metaxas T., Papadopoulos P., Kotoglou K., Stefanidis P., Christoulas K., Kyparos A., Mandroukas K. (2014) Acute partial passive stretching increases range of motion and muscle strength. J. Sports Med. Phys. Fitness, 54(3): 289-297.

39. Mao J.J., Palmer C.S., Healy K.E., Desai K., Amsterdam J. (2011) Complementary and alternative medicine use among cancer survivors: a population-based study. $J$. Cancer Surviv., 5(1): 8-17.

40. McCullough M.E., Hoyt W.T., Larson D.B., Koenig H.G., Thoresen C. (2000) Religious involvement and mortality: a meta-analytic review. Health Psychol., 19(3): 211-222.

41. Milanese M., Saporiti R., Bartolini S., Pellegrino R., Baroffio M., Brusasco V., Crimi E. (2009) Bronchodilator effects of exercise hyperpnea and albuterol in mildto-moderate asthma. J. Appl. Physiol. (1985), 107(2): 494-499.

42. Ornish D., Brown S.E., Scherwitz L.W., Billings J.H., Armstrong W.T., Ports T.A., McLanahan S.M., Kirkeeide R.L., Gould K.L., Brand R.J. (1990) Can lifestyle changes reverse coronary heart disease? The Lifestyle Heart Trial. The Lancet, 336(8708): 129-133.

43. Patel N.K., Newstead A.H., Ferrer R.L. (2012) The effects of yoga on physical functioning and health related quality of life in older adults: a systematic review and meta-analysis. J. Altern. Complement. Med., 18(10): 902-917.

44. Phoosuwan M., Kritpet T., Yuktananda P. (2009) The effects of weight bearing yoga training on the bone resorption markers of the postmenopausal women. J. Med. Assoc. Thai., 92: S102-S108.

45. Quilty M.T., Saper R.B., Goldstein R., Khalsa S.B. (2013) Yoga in the Real World: Perceptions, Motivators, Barriers, and Patterns of Use. Glob. Adv. Health Med., 2(1): 44-49.

46. Raghuram N., Parachuri V.R., Swarnagowri M.V., Babu S., Chaku R., Kulkarni R., Nagendra H.R. (2014) Yoga based cardiac rehabilitation after coronary artery bypass surgery: one-year results on LVEF, lipid profile and psychological states - a randomized controlled study. Indian Heart J., 66(5): 490-502.

47. Ramdev S. (2008) Maharishi Patanjali's Yogadarshana (the yoga philosophy). Uttarkhand. India. Divya Prakashan. 
48. Raupach T., Bahr F., Herrmann P., Luethje L., Heusser K., Hasenfuss G., Bernardi L., Andreas S. (2008) Slow breathing reduces sympathoexcitation in COPD. Eur. Respir. J., 32(2): 387-392.

49. Reed R.L., Pearlmutter L., Yochum K., Meredith K.E., Mooradian A.D. (1991) The relationship between muscle mass and muscle strength in the elderly. J. Am. Geriatr. Soc., 39(6): 555-561.

50. Ross A., Friedmann E., Bevans M., Thomas S. (2012) Frequency of yoga practice predicts health: results of a national survey of yoga practitioners. Evid. Based Complement. Alternat. Med., 2012: 983258.

51. Sharma M. (2014) Yoga as an alternative and complementary approach for stress management: a systematic review. J. Evid. Based Complement. Altern. Med, 19(1): 59-67.

52. Spicuzza L., Gabutti A., Porta C., Montano N., Bernardi L. (2000) Yoga and chemoreflex response to hypoxia and hypercapnia. The Lancet, 356(9240): 1495-1496.

53. Stec K. (2017) Dynamic Suryanamaskar - Sun Salutations. Delhi, India: Motilal Banarsidass.

54. Stec K. (2014) Effects of the yoga practice of Dynamic Suryanamaskar on the physiological, psychological, physical fitness and anthropometric characteristics of Indian students. Doctoral dissertation. Warsaw, Józef Pitsudski University of Physical Education, 1-176.

55. Stec K., Choudhary R. (2009) Effect of dynamic suryanamaskar on physical efficiency index of physical education students. Bangladesh J. Sport Sci., 9(1): 62-73.

56. Stec K., Choudhary R., Kulmatycki L. (2010) Effect of dynamic suryanamaskar on differential chest circumfer- ence of physical education students. Hum. Mov., 11(2): 179-183.

57. Stec K., Pilis K., Pilis W., Michalski C. (2016) Individual metabolic differences during Dynamic Suryanamaskar. Polish J. Sport Med., 32(3): 181-188.

58. Telles S., Naveen K.V. (1997) Yoga for rehabilitation: an overview. Indian J. Med. Sci., 51(4): 123-127.

59. Thayer S., Hansen A.L., Saus-Rose E., Johnsen B.H. (2009) Heart rate variability, prefrontal neural function, and cognitive performance: The neuro-visceral integration perspective on self-regulation, adaptation, and health. Ann. Behav. Med., 37: 141-153.

60. Tran M.D., Holly R.G., Lashbrook J., Amsterdam E.A. (2001) Effects of hatha yoga practice on the health-related aspects of physical fitness. Prev. Cardiol., 4: 165-170.

61. Venkatesananda S. (1993) Vashishtha's Yoga. State University of New York Press.

62. Vos T., Flaxman A.D., Naghavi M., Lozano R., Michaud C., Ezzati M., et al. (2012) Years lived with disability (YLDs) for 1160 sequelae of 289 diseases and injuries 1990-2010: a systematic analysis for the Global Burden of Disease Study 2010. Lancet, 380(9859): 2163-96.

\section{Received 02.10.2019 \\ Accepted 15.04.2020}

(C) University of Physical Education, Warsaw, Poland 